\title{
Synthesis and Antimicrobial Studies of Pyrimidine Pyrazole Heterocycles
}

\author{
Rakesh Kumar, ${ }^{1}$ Jyoti Arora, ${ }^{1,2}$ Sonam Ruhil, ${ }^{3}$ Neetu Phougat, ${ }^{3}$ \\ Anil K. Chhillar, ${ }^{3}$ and Ashok K. Prasad ${ }^{2}$ \\ ${ }^{1}$ Department of Chemistry, Bio-organic Laboratory, Kirori Mal College, University of Delhi, Delhi 110 007, India \\ ${ }^{2}$ Department of Chemistry, Bio-organic Laboratory, University of Delhi, Delhi 110 007, India \\ ${ }^{3}$ Centre for Biotechnology, Maharshi Dayanand University, Rohtak 124 001, India
}

Correspondence should be addressed to Rakesh Kumar; rakeshkp@email.com

Received 30 April 2014; Revised 19 July 2014; Accepted 29 July 2014; Published 25 August 2014

Academic Editor: Adriana I. Segall

Copyright (C) 2014 Rakesh Kumar et al. This is an open access article distributed under the Creative Commons Attribution License, which permits unrestricted use, distribution, and reproduction in any medium, provided the original work is properly cited.

\begin{abstract}
Prompted from the diversity of the wider use and being an integral part of genetic material, an effort was made to synthesize pyrimidine pyrazole derivatives of pharmaceutical interest by oxidative cyclization of chalcones with satisfactory yield and purity. A novel series of 1,3-dimethyl-6-hydroxy-2,4-dioxo-5-( $1^{\prime}$-phenyl-3' -aryl-1H-pyrazol-5' -yl)-1,2,3,4-tetrahydropyrimidines (5a-d) and 1,3-diaryl-6-hydroxy-4-oxo-2-thioxo-5-(1'-phenyl-3'-aryl-1H-pyrazol-5' -yl)-1,2,3,4-tetrahydropyrimidines (5e-1) has been synthesized. The structures of these compounds were established on the basis of FT-IR, ${ }^{1} \mathrm{H} \mathrm{NMR},{ }^{13} \mathrm{C}$ NMR, and mass spectral analysis. All the synthesized compounds were screened for their antimicrobial activity against bacteria and fungi. Among all the compounds, $\mathbf{5} \mathbf{g}$ was found to be the most active as its MIC was $31.25 \mu \mathrm{g} / \mathrm{mL}$ against $S$. aureus and B. cereus. The compounds $\mathbf{5 h}, \mathbf{5 c}$, and $\mathbf{5 e}$ also possess antibacterial activity with MIC values as $62.50,125.00$, and $500.00 \mu \mathrm{g} / \mathrm{mL}$, respectively. The compounds $\mathbf{5 c}$ and 5j were found to have antifungal activity against Aspergillus spp. As antifungal drugs lag behind the antibacterial drugs, therefore we tried in vitro combination of these two compounds with standard antifungal drugs (polyene and azole) against Aspergillus spp. The combination of ketoconazole with $\mathbf{5 c}$ and $\mathbf{5 j}$ showed synergy at $1: 8(6.25: 50.00 \mu \mathrm{g} / \mathrm{mL})$ and $1: 4(25: 100 \mu \mathrm{g} / \mathrm{mL}) \mathrm{against} A$. fumigatus (ITCC 4517) and A. fumigatus (VPCI 190/96), respectively.
\end{abstract}

\section{Introduction}

Nitrogen heterocycles are of special interest as they constitute an important class of natural and nonnatural products, many of which exhibit useful biological activities. Pyrimidine, being an integral part of DNA and RNA, imparts diverse pharmacological properties, such as bactericide, fungicide, vermicide, insecticide, and anticancer and antiviral agents [1]. Certain pyrimidine derivatives are also known to display antimalarial, antifilarial, and antileishmanial activities [2].

The pyrazole derivatives are well known to have antimicrobial [3], antifungal [4], antitubercular [5], anticancer [6], analgesic [7], anti-inflammatory [8], antipyretic [9], anticonvulsant [10], antidepressant [11], muscle relaxing [12], antiulcer [13], antiarrhythmic [14], and antidiabetic [15] activities. With growing application of their synthesis and bioactivity, chemists and biologists in recent years have directed considerable attention to the study of pyrazole derivatives. In view of the above mentioned importance of pyrimidines and pyrazoles, we tried to accommodate these moieties in a single molecular framework to synthesize the linked heterocycles for enhancing biological activity.

\section{Results and Discussion}

2.1. Chemistry. (E)-1-(1', $3^{\prime}$-Dimethyl-6'-hydroxy-2', $4^{\prime}$-dioxo$1^{\prime}, 2^{\prime}, 3^{\prime}, 4^{\prime}$-tetrahydropyrimidin- $5^{\prime}$-yl)-3-aryl-prop-2-ene-1ones (4a-d) and $(E)-1-\left(1^{\prime}, 3^{\prime}\right.$-diaryl- $6^{\prime}$-hydroxy- $4^{\prime}$-oxo- $2^{\prime}$ thiooxo-1 $1^{\prime}, 2^{\prime}, 3^{\prime}, 4^{\prime}$-tetrahydropyrimidin- $5^{\prime}$-yl)-3-aryl-prop2 -ene-1-ones $(\mathbf{4} \mathbf{e}-\mathbf{l})$ were synthesized by the Claisen condensation of 5-acetyl barbituric/thiobarbituric acid (2a-c) with aromatic aldehydes $\mathbf{3 a} \mathbf{a} \mathbf{d}$ in methanol in the presence of $\mathrm{NaOH}$ as a base at $60^{\circ} \mathrm{C}$ [16]. Further, cyclocondensation of propenones $\mathbf{4 a - 1}$ with phenylhydrazine in acidic condition 
in dioxane as solvent yielded 1,3-dimethyl-6-hydroxy-2,4dioxo-5-( $1^{\prime}$ - phenyl-3' - aryl-1H-pyrazol-5' -yl)-1,2,3,4- tetrahydropyrimidines (5a-d) and 1,3-diaryl-6-hydroxy-4-oxo-2thioxo-5-(1' - phenyl-3' -aryl-1H-pyrazol-5' -yl)-1,2,3,4-tetrahydropyrimidines $(5 \mathbf{e}-\mathbf{l})$ in $46-81 \%$ yields [17]. Structure and yield of compounds, that is, $\mathbf{4 a - 1}$ and $\mathbf{5 a}-\mathbf{l}$, are listed in Table 1. The 5-acetyl-1,3-diarylthiobarbituric acids (2b-c) in turn were synthesized by the following known method from 1,3-diarylthiobarbituric acids (1b-c) and acetic anhydride $[18,19]$ (Scheme 1).

All the compounds synthesized were characterized by IR, ${ }^{1} \mathrm{H}$ NMR, ${ }^{13} \mathrm{C}$ NMR, and mass spectroscopy. Spectroscopic data was in complete agreement with the structures assigned for these compounds. IR spectrum of cyclized derivatives of barbituric acid (5a-d) showed band in the region of $1700-$ $1740 \mathrm{~cm}^{-1}$ for carbonyl group (at C2). The other carbonyl group at C4 showed band in the region of $1640-1699 \mathrm{~cm}^{-1}$, whereas cyclized derivatives of thiobarbituric acid (5e-1) showed band in the region of $1050-1100 \mathrm{~cm}^{-1}$, which indicates the presence of thiocarbonyl group (at C2) and other carbonyl groups at C4 showed band in the region of 1625$1680 \mathrm{~cm}^{-1}$. Frequency band of $\mathrm{OH}$ group appears at 3200$3450 \mathrm{~cm}^{-1}$ in the compounds $\mathbf{5 a - 1}$. In ${ }^{1} \mathrm{H}$ NMR spectra, chemical shift values of all the compounds were in accordance with the expected values. Aromatic protons of compounds $4 \mathbf{a}-\mathbf{l}$ resonated in the region of $\delta 6.86-7.82$. Two doublets of $\alpha$ $\mathrm{H}$ (attached to $\mathrm{C} 2$ ) at $\delta 8.06(J=16.11 \mathrm{~Hz})$ and $\beta-\mathrm{H}$ (attached to $\mathrm{C} 3)$ at $8.41(J=16.11 \mathrm{~Hz})$, respectively, of $\mathbf{4 f}$ demonstrate the formation of $\alpha, \beta$-unsaturated carbonyl moiety and $J=$ $16.11 \mathrm{~Hz}$ indicates that the ethylene moiety in the enone linkage is in trans confirmation in the chalcone. Disappearance of these doublets in $\mathbf{5} \mathbf{f}$ indicates the absence of chalcone moiety. All other phenyl protons in the compounds $\mathbf{5 a}-\mathbf{l}$ appeared in the aromatic region at $\delta 6.82-7.58$. In ${ }^{13} \mathrm{C} \mathrm{NMR}$ of $4 \mathbf{f}$, all the characteristic peaks were in good agreement with the proposed structure. Carbonyl carbon at C-1 and C-4' appeared at $\delta 184.6$ and 168.2, respectively. The characteristic peak of $\mathrm{C}=\mathrm{S}$ appeared at $\delta$ 178.9. The $\mathrm{C}-2$ and $\mathrm{C}-3$ carbons appeared at $\delta 114.5$ and 139.7, respectively. The $\mathrm{OCH}_{3}$ carbon appeared at $\delta 55.4$. The aromatic carbons attached to $\mathrm{OCH}_{3}$ (i.e., C- $4^{\prime \prime}$ ) appeared at $\delta$ 162.9. The other aromatic carbons of $\mathbf{4 f}$ resonated in the region of $\delta 127.3-131.7$ and the aromatic carbon attached to nitrogen appeared at 148.6. In ${ }^{13} \mathrm{C}$ NMR of 5f, disappearance of peak at $\delta 184.6$ indicates the cyclization of chalcone. Carbonyl carbon at C-4 appeared at $\delta 164.0$. The characteristic peak of $\mathrm{C}=\mathrm{S}$ appeared at $\delta 180.0$. C-6 carbon appeared at $\delta 160.8$. The pyrazole carbon at C- $4^{\prime}$ appeared at $\delta$ 88.3 [20]. The $\mathrm{OCH}_{3}$ carbon appeared at $\delta$ 55.3. The aromatic carbon attached to $\mathrm{OCH}_{3}$, that is, $\mathrm{C}-4^{\prime \prime}$, appeared at $\delta 161.4$. The other aromatic carbons resonated in the region of $\delta 127.4-$ 129.5 and the aromatic carbon attached to nitrogen appeared at $\delta$ 147.13. Details of ${ }^{1} \mathrm{H}$ NMR and ${ }^{13} \mathrm{C}$ NMR spectra of $\mathbf{5 a - 1}$ are given in experimental section.

\subsection{Biology}

2.2.1. Antifungal Activity. The antifungal activity against Aspergillus spp. was evaluated by different methods [21-23], that is, disc diffusion assay (DDA), microbroth dilution assay (MDA), and percent spore germination inhibition (PSGI). The Minimum Inhibitory Concentration (MIC) values of Amphotericin B (Amp B) and Nystatin (NYS) against all the three Aspergillus species were found to be $0.75 \mu \mathrm{g} / \mathrm{disc}$ and $1.00 \mu \mathrm{g} /$ disc, respectively, by DDA and $1.95 \mu \mathrm{g} / \mathrm{mL}$ and $3.90 \mu \mathrm{g} / \mathrm{mL}$, respectively, by MDA and PSGI. The MIC of $5 \mathrm{c}$ compound was $46.75 \mu \mathrm{g} / \mathrm{disc}$ against all the tested isolates of Aspergillus spp. by DDA, whereas $5 \mathbf{j}$ compound possesses a slight higher MIC against $A$. flavus and $A$. niger, that is, $187.5 \mu \mathrm{g} /$ disc, but against $A$. fumigatus it possesses the same MIC, that is, $46.75 \mu \mathrm{g} / \mathrm{disc}$. The MIC of $5 \mathrm{c}$ by MDA and PSGI was found to be $250.0 \mu \mathrm{g} / \mathrm{mL}$ against $A$. fumigatus and $500.0 \mu \mathrm{g} / \mathrm{mL}$ against $A$. flavus and $A$. niger. The MIC of $5 \mathbf{j}$ was found to be $500.0 \mu \mathrm{g} / \mathrm{mL}$ against $A$. fumigatus and $A$. flavus and $1000 \mu \mathrm{g} / \mathrm{mL}$ against $A$. niger, respectively, by MDA and PSGI (Table 2).

Results revealed that the synthesized compounds $5 \mathrm{c}$ and 5j exhibited mild antifungal activity which is lower than the standard drugs. Some other substituted pyrimidines and pyrazoles have earlier been reported as potent antifungal agents against a number of pathogenic fungi alone and in combination $[24,25]$.

As these compounds showed promising activity, so we further tried these compounds in combination with standard antifungal drugs to evaluate their synergistic behaviour, if any. Therefore, the compounds $\mathbf{5} \mathbf{c}$ and $\mathbf{5 j}$ were tried for in vitro combination with polyenes and azoles.

(1) In Vitro Combination Study of Pyrimidine Pyrazole Analogues (5c and 5j) with Antifungal Drugs. Among the human pathogenic species of Aspergillus, A. fumigatus is the primary causative agent of human infection followed by $A$. flavus and A. niger [23]. Therefore, A. fumigatus [ITCC 4517 (IARI, Indian Agricultural Research Institute, Delhi), ITCC 1634, clinical isolate VPCI 190/96 (VPCI, Vallabhbhai Patel Chest Institute, Delhi)] was selected for in vitro combination study of pyrimidine pyrazole analogues with antifungal drugs. The data of in vitro combination was analysed by Fraction Inhibitory Concentration Index (FICI) model [24] and summarized in Tables 3-6.

(1.1) In Vitro FIC Index of 5c with Polyene (Amp B, NYS) and Azole (KTZ, FLZ). In combination of Amp B and NYS with $5 \mathrm{c}$, the FICI values were found to be in the range of 0.8 to 1.03 ; indifference (IND) was declared against $A$. fumigatus strains (Table 3). The MIC end point value of $\mathbf{5} \mathbf{c}$ reduced from 314.98 to $7.87 / 12.50 \mu \mathrm{g} / \mathrm{mL}$. But the MIC of Amp B and NYS almost remains the same, that is, $1.96 \mu \mathrm{g} / \mathrm{mL}$ and $3.12 \mu \mathrm{g} / \mathrm{mL}$.

The combination of $5 \mathrm{c}$ with KTZ and FLZ reduced the MIC end point value of KTZ and FLZ from 39.37 to $7.87 \mu \mathrm{g} / \mathrm{mL}$ and from 314.98 to $62.90 \mu \mathrm{g} / \mathrm{mL}$, respectively, against $A$. fumigatus strains. The MIC of $5 \mathrm{c}$ reduced from 314.98 to $62.90 \mu \mathrm{g} / \mathrm{mL}$ in combination with $\mathrm{KTZ}$ and with FLZ it gets reduced to 251.98. Depending upon FICI model indifference (IND) and synergy (SYN) was observed. The combination of KTZ with 5c showed SYN against only one strain of $A$. fumigatus, that is, ITCC 4517 , at $1: 8$ $(6.25: 50.00 \mu \mathrm{g} / \mathrm{mL}$, FICI $=0.40)($ Table 4$)$. The FICI $(\mathrm{GM})$ 


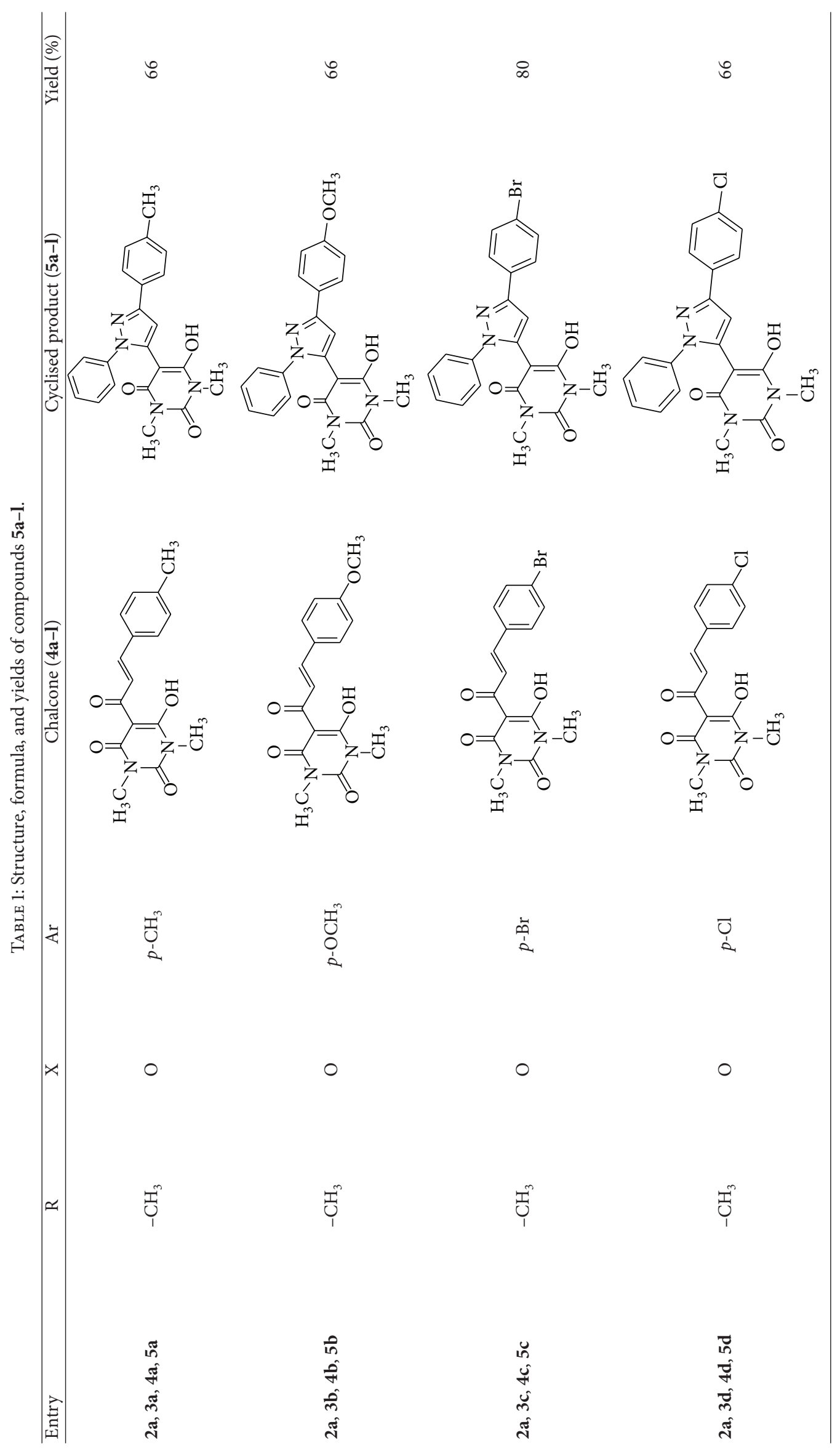




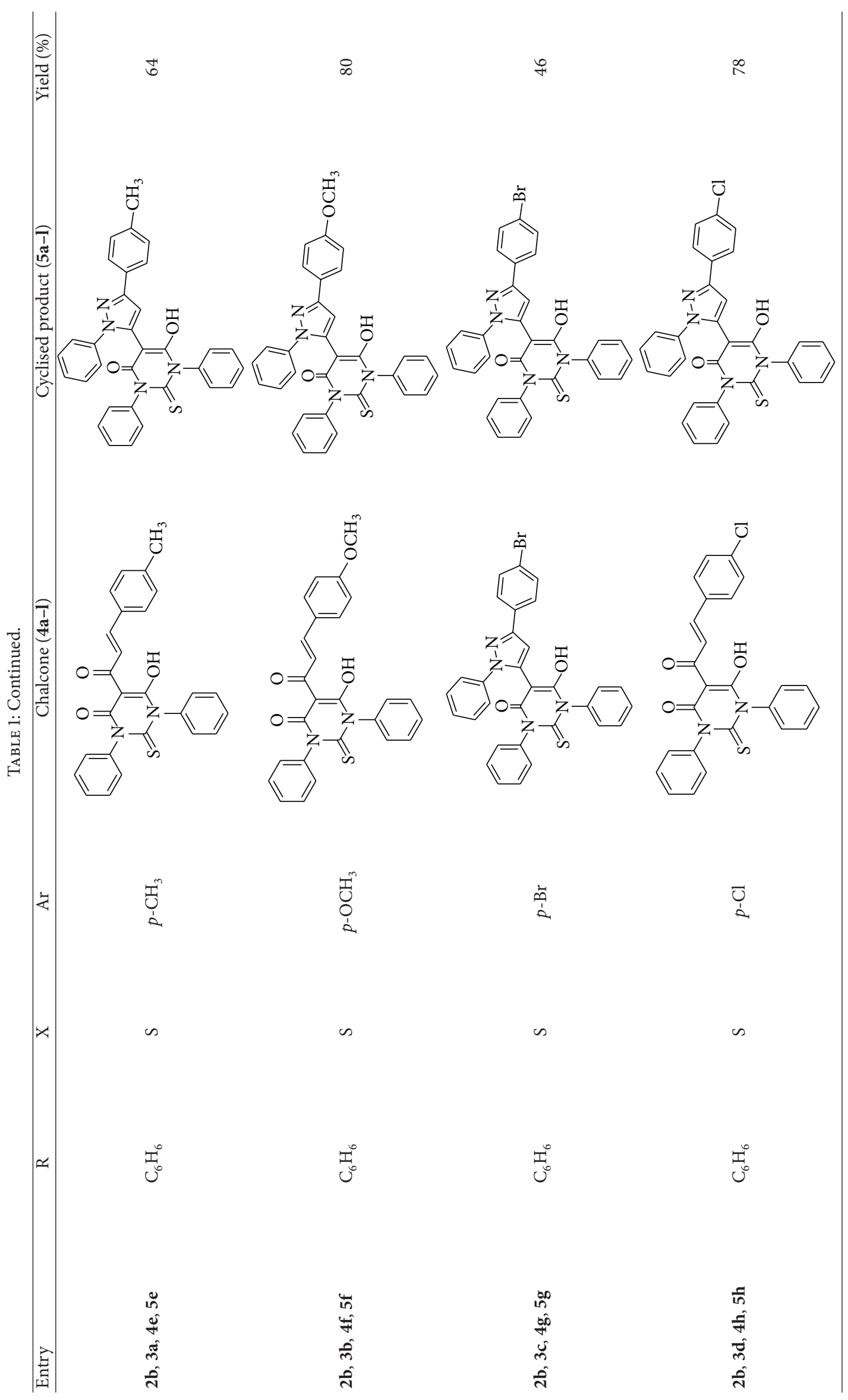




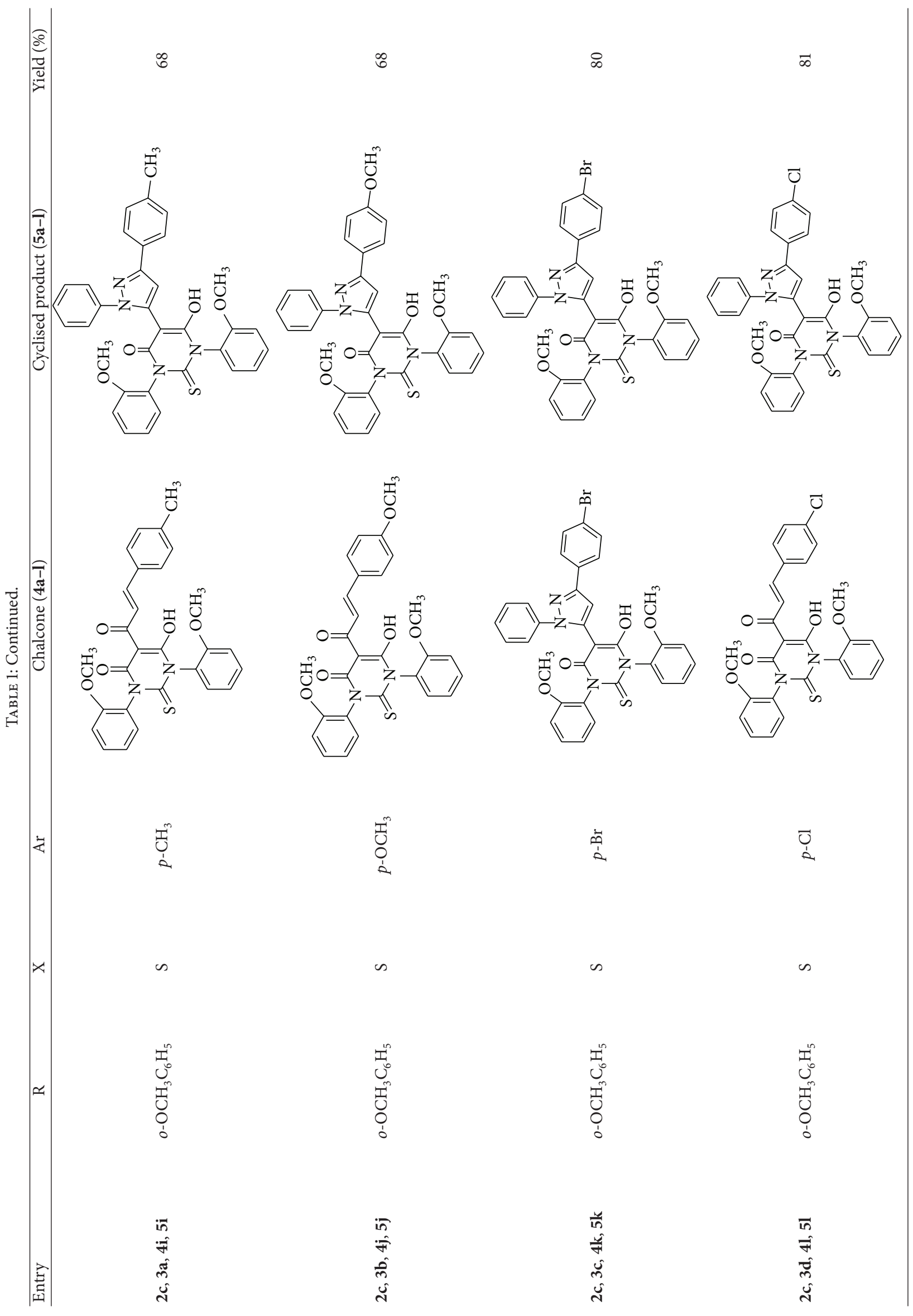


TABLE 2: Antifungal activity of pyrimidine pyrazole analogues.

\begin{tabular}{|c|c|c|c|c|c|c|c|c|c|}
\hline \multirow{3}{*}{ Compound } & \multicolumn{9}{|c|}{ MIC } \\
\hline & \multicolumn{3}{|c|}{ DDA ( $\mu \mathrm{g} / \mathrm{disc})$} & \multicolumn{3}{|c|}{$\operatorname{MDA}(\mu \mathrm{g} / \mathrm{mL})$} & \multicolumn{3}{|c|}{ PSGI $(\mu \mathrm{g} / \mathrm{mL})$} \\
\hline & A. flavus & A. niger & A. fumigatus & A. flavus & A. niger & A. fumigatus & A. flavus & A. niger & A. fumigatus \\
\hline$\overline{5 c}$ & 46.75 & 46.75 & 46.75 & 500 & 500 & 250 & 500 & 500 & 250 \\
\hline $5 e$ & - & - & - & - & - & - & - & - & - \\
\hline $5 f$ & - & - & - & - & - & - & - & - & - \\
\hline $5 \mathrm{~g}$ & - & - & - & - & - & - & - & - & - \\
\hline $5 \mathrm{~h}$ & - & - & - & - & - & - & - & - & - \\
\hline $5 i$ & - & - & - & - & - & - & - & - & - \\
\hline $5 \mathbf{j}$ & 187.5 & 187.5 & 46.75 & 500 & 1000 & 500 & 500 & 1000 & 500 \\
\hline $5 k$ & - & - & - & - & - & - & - & - & - \\
\hline 51 & - & - & - & - & - & - & - & - & - \\
\hline
\end{tabular}

TABLE 3: In vitro combination of compound $\mathbf{5 c}$ with polyene (AmpB, NYS) against A. fumigatus.

\begin{tabular}{lccccccccc}
\hline \multirow{2}{*}{ Strain } & \multicolumn{4}{c}{ MIC $(\mu \mathrm{g} / \mathrm{mL})$} & \multicolumn{2}{c}{ FIC index } & \multicolumn{3}{c}{ Interpretation } \\
& $\mathbf{5 c}$ & AmpB & NYS & AmpB $+\mathbf{5 c}$ & NYS $+\mathbf{5 c}$ & AmpB $+\mathbf{5 c}$ & NYS $+\mathbf{5 c}$ & AmpB $+\mathbf{5 c}$ & NYS $+\mathbf{5 c}$ \\
\hline ITCC 4517 & 250 & 1.95 & 3.9 & $1.56 / 6.25$ & $3.12 / 12.50$ & $0.83(0.8+0.03)$ & $0.85(0.8+0.05)$ & IND & IND \\
ITCC 1634 & 500 & 1.95 & 3.9 & $3.12 / 12.50$ & $3.12 / 12.50$ & $1.62(1.6+0.02)$ & $0.83(0.8+0.03)$ & IND & IND \\
VPCI 190/96 & 250 & 1.95 & 3.9 & $1.56 / 6.25$ & $3.12 / 12.50$ & $0.83(0.8+0.03)$ & $0.85(0.8+0.05)$ & IND & IND \\
\hline Geometric mean & 314.98 & 1.95 & 3.9 & $1.96 / 7.87$ & $3.12 / 12.50$ & $1.03(1.00+0.3)$ & $0.83(0.8+0.03)$ & IND & IND \\
\hline
\end{tabular}

IND: indifference.

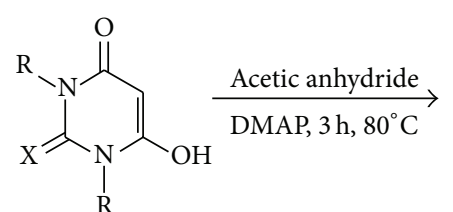

1a-c<smiles></smiles>

4a-1<smiles></smiles>

$2 a-c$

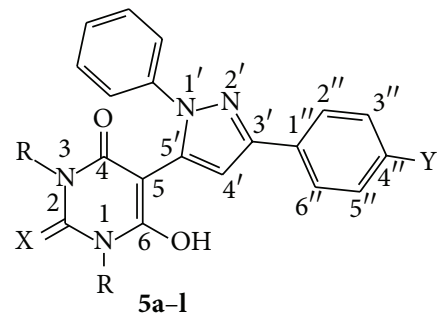

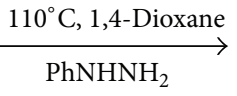
$\mathrm{PhNHNH}_{2}$

\begin{tabular}{lcc}
$\begin{array}{l}\text { Compounds } \\
\mathbf{1}-\mathbf{5}\end{array}$ & $\mathrm{R}$ & $\mathrm{X}$ \\
\hline $\mathbf{1 a}, \mathbf{2 a}, \mathbf{4 a}-\mathbf{d}$, & $-\mathrm{CH}_{3}$ & $\mathrm{O}$ \\
$\mathbf{5 a - d}$ & & \\
$\mathbf{1 b}, \mathbf{2 b}, \mathbf{4} \mathbf{e}-\mathbf{h}$, & $-\mathrm{C}_{6} \mathrm{H}_{5}$ & $\mathrm{~S}$ \\
$\mathbf{5 e - h}$ & & \\
$\mathbf{1 c}, \mathbf{2 c}, \mathbf{4 i - 1}$, & ${ }^{-}-\mathrm{OCH}_{3} \mathrm{C}_{6} \mathrm{H}_{4}$ & $\mathrm{~S}$ \\
$\mathbf{5 i - 1}$ & &
\end{tabular}

\begin{tabular}{lc}
$\begin{array}{l}\text { Compounds } \\
\text { 3-5 }\end{array}$ & $\mathrm{Y}$ \\
\hline $\begin{array}{l}\text { 3a, 4a, 4e, } \\
\text { 4i, 5a, 5e, 5i }\end{array}$ & $\mathrm{CH}_{3}$ \\
$\begin{array}{l}\text { 3b, 4b, 4f, } \\
\text { 4j, 5b, 5f, 5j }\end{array}$ & $\mathrm{OCH}_{3}$ \\
3c, 4c, 4g, & $\mathrm{Br}$ \\
$\begin{array}{l}\text { 4k, 5c, 5g, 5k } \\
\text { 3d, 4d, 4h, }\end{array}$ & \\
4l, 5d, 5h, 5l & $\mathrm{Cl}$
\end{tabular}

Scheme 1: Synthesis of pyrimidine pyrazole derivatives. 
TABLE 4: In vitro combination of compound $\mathbf{5 c}$ with azole (KTZ, FLZ) against $A$. fumigatus.

\begin{tabular}{lccccccccc}
\hline \multirow{2}{*}{ Strain } & \multicolumn{4}{c}{ MIC $(\mu \mathrm{g} / \mathrm{mL})$} & \multicolumn{2}{c}{ FIC index } & \multicolumn{3}{c}{ Interpretation } \\
& $\mathbf{5 c}$ & KTZ & FLZ & KTZ + 5c & FLZ + 5c & KTZ + 5c & FLZ + 5c & KTZ + 5c & FLZ + 5c \\
\hline ITCC 4517 & 250 & 31.25 & 500 & $6.25 / 50.0$ & $50.0 / 200.0$ & $0.40(0.2+0.2)$ & $0.9(0.1+0.8)$ & SYN & IND \\
ITCC 1634 & 500 & 62.50 & 250 & $25.0 / 100.0$ & $100.0 / 400.0$ & $0.60(0.4+0.2)$ & $1.2(0.4+0.8)$ & IND & IND \\
VPCI 190/96 & 250 & 31.25 & 250 & $12.50 / 50.0$ & $50.0 / 200.0$ & $0.60(0.4+0.2)$ & $1.0(0.2+0.8)$ & IND & IND \\
\hline Geometric mean & 314.98 & 39.37 & 314.98 & $7.87 / 62.9$ & $62.9 / 251.98$ & $0.52(0.32+0.20)$ & $1.0(0.2+0.8)$ & IND & IND \\
\hline
\end{tabular}

IND: indifference; SYN: synergy.

TABLE 5: In vitro combination of compound $5 \mathbf{j}$ with polyene (AmpB, NYS) against A. fumigatus.

\begin{tabular}{lccccccccc}
\hline \multirow{2}{*}{ Strain } & \multicolumn{4}{c}{ MIC $(\mu \mathrm{g} / \mathrm{mL})$} & \multicolumn{2}{c}{ FIC index } & \multicolumn{3}{c}{ Interpretation } \\
& $\mathbf{5 j}$ & AmpB & NYS & AmpB + 5j & NYS + 5j & AmpB + 5j & NYS + 5j & AmpB + 5j & NYS + 5j \\
\hline ITCC 4517 & 250.00 & 1.95 & 3.90 & $1.56 / 6.25$ & $3.12 / 12.50$ & $0.83(0.8+0.03)$ & $0.85(0.8+0.05)$ & IND & IND \\
ITCC 1634 & 500.00 & 1.95 & 3.90 & $3.12 / 12.50$ & $6.25 / 25.00$ & $1.62(1.6+0.02)$ & $1.65(1.6+0.05)$ & IND & IND \\
VPCI 190/96 & 500.00 & 1.95 & 3.90 & $1.56 / 3.12$ & $3.12 / 12.50$ & $0.81(0.8+0.01)$ & $0.83(0.8+0.03)$ & IND & IND \\
\hline Geometric mean & 396.85 & 1.95 & 3.90 & $1.96 / 6.24$ & $3.93 / 15.70$ & $1.03(1.00+0.3)$ & $1.05(1.00+0.5)$ & IND & IND \\
\hline
\end{tabular}

IND: indifference.

values for the rest of combination were 0.52 and 1.02; IND occurred.

Since the MIC value of KTZ is significantly reduced in combination with $\mathbf{5 c}$, this compound may be a potential candidate for further research and may be developed as a potential candidate to be used in combination therapy against fungal infections.

(1.2) In Vitro FIC Index of $\mathbf{5 j}$ with Polyene (Amp B, NYS) and Azole (KTZ, FLZ). The MIC (GM) end point value of Amp $B$ and NYS in combination with $5 \mathbf{j}$ remains almost the same, that is, 1.96 and $3.93 \mu \mathrm{g} / \mathrm{mL}$, respectively. But the MIC (GM) end point value of $\mathbf{5} \mathbf{j}$ in combination with Amp B and NYS reduced from 396.84 to 6.24 and $15.70 \mu \mathrm{g} / \mathrm{mL}$, respectively. The FICI (GM) values were found to be 1.03 and 1.05 with Amp B and NYS combination with $5 \mathbf{j}$; showed IND against the tested strain (Table 5).

The combination of azole (KTZ and FLZ) with $5 \mathbf{j}$ reduced the MIC (GM) end point value of KTZ from 39.33 to 25.00 and from 314.98 to $62.99 \mu \mathrm{g} / \mathrm{mL}$ of FLZ. The MIC (GM) end point value of $5 \mathbf{j}$ reduced from 396.85 to $100 \mu \mathrm{g} / \mathrm{mL}$ with $\mathrm{KTZ}$ and $251.98 \mu \mathrm{g} / \mathrm{mL}$ with FLZ. But this reduction is not as much significant as the combination of $\mathrm{KTZ}$ with $5 \mathbf{j}$, which showed synergy against only one A. fumigatus VPCI 190/96, that is, $1: 4(25: 100 \mu \mathrm{g} / \mathrm{mL})$. The FICI (GM) values for the other combinations were 0.70 and 0.83 ; indifference was declared (Table 6).

2.2.2. Antibacterial Activity. Among all the analogues the most active compound was $5 \mathrm{~g}$ whose MIC was $31.25 \mu \mathrm{g} / \mathrm{mL}$ against $S$. aureus and $B$. cereus and the second and third most active compounds were $5 \mathbf{h}$ and $5 \mathrm{c}$ which showed MIC at $62.50 \mu \mathrm{g} / \mathrm{mL}$ against B. cereus and S. aureus and $125 \mu \mathrm{g} / \mathrm{mL}$ against $S$. aureus, respectively. The other two compounds $5 \mathbf{e}$ and $5 \mathbf{j}$ showed activity at $500 \mu \mathrm{g} / \mathrm{mL}$ against $S$. aureus and $E$. coli, respectively. Erythromycin was used as a standard drug (Table 7).
It has already been reported that the pyrimidine pyrazole analogues have strong antibacterial activity against a number of pathogenic bacteria [26]. Therefore, we have tried to evaluate their in vitro antibacterial potential against gram positive as well as gram negative bacteria.

The compound $\mathbf{5 g}$ showed potent antibacterial activity against gram positive bacteria $S$. aureus and $B$. cereus. These results suggest that there may be a useful practical application from the chemistry of pyrimidine pyrazole analogues.

\section{Experimental}

3.1. General. All reagents were of commercial grade and were used as received. Solvents were dried and purified using standard techniques. ${ }^{1} \mathrm{H}-\mathrm{NMR}(400 \mathrm{MHz})$ and ${ }^{13} \mathrm{C}-\mathrm{NMR}$ (100.5 MHz) were recorded on JNM ECX-400P (Jeol, USA) spectrometer using TMS as an internal standard. Chemical shifts are reported in parts per million ( $\mathrm{ppm}$ ). Mass spectra were recorded on API-2000 mass spectrometer. IR absorption spectra were recorded in the $400-4000 \mathrm{~cm}^{-1}$ range on a Perkin-Elmer FT-IR spectrometer model 2000 using $\mathrm{KBr}$ pallets. Melting points were determined using Buchi M-560 and are uncorrected. These reactions were monitored by thin layer chromatography (TLC), on aluminium plates coated with silica gel $60 \mathrm{~F}_{254}$ (Merck). UV radiation and iodine were used as the visualizing agents. Column chromatography was performed on silica gel (100-200 mesh).

3.2. General Procedure for the Synthesis of Chalcone Analogues $(4 \boldsymbol{a}-\mathbf{l})$. A solution of $2 \mathbf{a}-\mathbf{c}(1 \mathrm{mmol})$ and corresponding aryl aldehydes $3 \mathbf{a}-\mathbf{d}(1 \mathrm{mmol})$ in $20 \mathrm{~mL}$ of methanol was treated with sodium hydroxide as base at $60^{\circ} \mathrm{C}$. The reaction mixture was refluxed for $50 \mathrm{~h}$. After completion of reaction, it was concentrated and extracted with chloroform $(3 \times 20 \mathrm{~mL})$. The combined organic extract was dried over anhydrous sodium sulphate and concentrated under reduced pressure. The crude product was purified by column chromatography. 
TABLE 6: In vitro combination of compound 5j with azole (KTZ and FLZ) against A. fumigatus.

\begin{tabular}{lcccccccccc}
\hline \multirow{2}{*}{ Strain } & \multicolumn{4}{c}{ MIC $(\mu \mathrm{g} / \mathrm{mL})$} & \multicolumn{3}{c}{ FIC index } & \multicolumn{3}{c}{ Interpretation } \\
& $\mathbf{5 j}$ & KTZ & FLZ & KTZ + 5j & FLZ + 5j & KTZ + 5j & FLZ + 5j & KTZ + 5j & FLZ + 5j \\
\hline ITCC 4517 & 250.00 & 31.25 & 500.00 & $25.00 / 100.00$ & $50.00 / 200.00$ & $1.20(0.8+0.4)$ & $0.90(0.1+0.8)$ & IND & IND \\
ITCC 1634 & 500.00 & 62.50 & 250.00 & $25.00 / 100.00$ & $100.00 / 400.00$ & $0.60(0.4+0.2)$ & $1.20(0.4+0.8)$ & IND & IND \\
VPCI 190/96 & 500.00 & 31.25 & 250.00 & $25.0 / 100.00$ & $50.00 / 200.00$ & $0.50(0.4+0.1)$ & $0.60(0.2+0.4)$ & SYN & IND \\
\hline Geometric mean & 396.85 & 39.37 & 314.90 & $25.00 / 100.00$ & $62.99 / 251.98$ & $0.7(0.5+0.2)$ & $0.83(0.2+0.63)$ & IND & IND \\
\hline
\end{tabular}

IND: indifference.

TABLE 7: Antibacterial activity of pyrimidine pyrazole analogues.

\begin{tabular}{lccccccc}
\hline \multirow{2}{*}{ Compound } & \multicolumn{7}{c}{ Bacterial pathogens $(\mathrm{MIC} \mu \mathrm{g} / \mathrm{mL})$} \\
\hline $\mathbf{5 c}$ & S. aureus & B. cereus & E. coli & S. typhi & M. luteus & B. pumilus & B. subtilis \\
$\mathbf{5 e}$ & 125 & - & - & - & - & - & - \\
$\mathbf{5}$ & 500 & - & - & - & - & - & - \\
$\mathbf{5}$ & - & - & - & - & - & - & - \\
$\mathbf{5}$ & 31.25 & 31.25 & - & - & - & - & - \\
$\mathbf{5}$ & 62.50 & 62.50 & - & - & - & - & - \\
$\mathbf{5}$ & - & - & - & - & - & - & - \\
$\mathbf{5}$ & - & - & - & - & - & - & - \\
$\mathbf{5}$ & - & - & - & - & - & - & - \\
ERY & - & - & - & - & - & 15.62 & 15.62 \\
\hline
\end{tabular}

ERY: erythromycin (standard drug).

-: no significant inhibition.

3.2.1. (E)-1-(1', $3^{\prime}$-Dimethyl- $6^{\prime}$ - hydroxy- $2^{\prime}, 4^{\prime}$-dioxo- $1^{\prime}, 2^{\prime}, 3^{\prime}, 4^{\prime}-$ tetrahydropyrimidin-5'-yl)-3-(p-tolyl)-prop-2-ene-1-one, $(\mathbf{4 a})$. The product was obtained as mentioned in general procedure from $2 \mathbf{a}$ and $3 \mathbf{a}$ as yellow solid in $72 \%$ yield; M.p. $187.0^{\circ} \mathrm{C}$; IR $\nu_{\max }\left(\mathrm{cm}^{-1}\right)=1662,1718(\mathrm{C}=\mathrm{O}), 2925(\mathrm{C}-\mathrm{H}), 3432(\mathrm{OH}) ;{ }^{1} \mathbf{H}$ NMR $\left(400 \mathrm{MHz}, \mathrm{CDCl}_{3}\right): \delta(\mathrm{ppm}) 2.34\left(3 \mathrm{H}, \mathrm{s},-\mathrm{CH}_{3}\right), 3.20$ $\left(6 \mathrm{H}, \mathrm{s}, \mathrm{N}-\mathrm{CH}_{3}\right), 7.29(2 \mathrm{H}, \mathrm{d}, J=7.32 \mathrm{~Hz}, \mathrm{ArH}), 7.62(2 \mathrm{H}$, $\mathrm{d}, J=8.04 \mathrm{~Hz}, \mathrm{ArH}), 7.95(1 \mathrm{H}, \mathrm{d}, J=16.11 \mathrm{~Hz}, \alpha-\mathrm{H}) 8.45$ $(1 \mathrm{H}, \mathrm{d}, J=16.11 \mathrm{~Hz}, \beta-\mathrm{H}), 16.94(1 \mathrm{H}, \mathrm{s},-\mathrm{OH}) ;{ }^{13} \mathrm{C}$ NMR $\left(100 \mathrm{MHz}, \mathrm{CDCl}_{3}\right): \delta(\mathrm{ppm}) 21.05,27.67,27.84,119.10,126.37$, $128.43,129.00,129.98,131.85,139.38,141.81,145.65,149.84$, $154.69,163.22,165.83,182.02$.

3.2.2. (E)-1-(1', $3^{\prime}$-Diphenyl-6'-hydroxy-4'-oxo- $2^{\prime}$-thiooxo- $1^{\prime}, 2^{\prime}$, $3^{\prime}, 4^{\prime}$-tetrahydropyrimidin- $5^{\prime}$-yl)-3-(p-tolyl)-prop-2-ene-1-one, $(4 e)$. The product was obtained as mentioned in general procedure from $\mathbf{2 b}$ and $\mathbf{3 a}$ as yellow solid in $67 \%$ yield; M.p. $284.6^{\circ} \mathrm{C}$; IR $v_{\max }\left(\mathrm{cm}^{-1}\right)=1039(\mathrm{C}=\mathrm{S}), 1690(\mathrm{C}=\mathrm{O})$, $2924(\mathrm{C}-\mathrm{H}), 3433(\mathrm{OH}) ;{ }^{1} \mathrm{H}$ NMR $\left(400 \mathrm{MHz}, \mathrm{CDCl}_{3}\right): \delta$ (ppm) $2.38\left(3 \mathrm{H}, \mathrm{s},-\mathrm{CH}_{3}\right), 7.18(2 \mathrm{H}, \mathrm{d}, J=8.05 \mathrm{~Hz}, \mathrm{ArH})$, 7.28-7.31 (2H, m, ArH), 7.45-7.58 (10H, m, ArH), $8.09(1 \mathrm{H}$, d, $J=15.38 \mathrm{~Hz}, \alpha-\mathrm{H}), 8.51(1 \mathrm{H}, \mathrm{d}, J=16.84 \mathrm{~Hz}, \beta-\mathrm{H}), 16.79$ $(1 \mathrm{H}, \mathrm{s},-\mathrm{OH}) ;{ }^{13} \mathrm{C}$ NMR $\left(100 \mathrm{MHz}, \mathrm{CDCl}_{3}\right): \delta(\mathrm{ppm}) 21.68$ $\left(-\mathrm{CH}_{3}\right), 119.15,128.55,128.63,128.77,129.11,129.55,129.61$, $129.67,129.81,131.82,139.72,142.96,148.62,159.94,168.63$, $178.74(\mathrm{C}=\mathrm{S}), 185.18$.
3.2.3. (E)-1-( $\left(1^{\prime}, 3^{\prime}-\operatorname{Bis}\left(2^{\prime \prime}{ }^{\prime}\right.\right.$-methoxyphenyl $)-6^{\prime}-$ hydroxy- $4^{\prime}$-oxo$2^{\prime}$-thiooxo-1 $1^{\prime}, 2^{\prime}, 3^{\prime} 4^{\prime}$-tetrahydro pyrimidin- $\left.5^{\prime}-y l\right)-3$-( $p$-tolyl)prop-2-ene-1-one, $(\mathbf{4 i})$. The product was obtained as mentioned in general procedure from $2 \mathrm{c}$ and $\mathbf{3 a}$ as yellow solid in $68 \%$ yield; M.p. $220.5^{\circ} \mathrm{C}$; IR $v_{\max }\left(\mathrm{cm}^{-1}\right)=1025$ $(\mathrm{C}=\mathrm{S}), 1663(\mathrm{C}=\mathrm{O}), 2926(\mathrm{C}-\mathrm{H}), 3434(\mathrm{OH}) ;{ }^{1} \mathrm{H}$ NMR $\left(400 \mathrm{MHz}, \mathrm{CDCl}_{3}\right): \delta(\mathrm{ppm}) 2.35\left(3 \mathrm{H}, \mathrm{s},-\mathrm{CH}_{3}\right), 3.84(6 \mathrm{H}$, $\left.\mathrm{s},-\mathrm{OCH}_{3}\right), 7.03-7.10(4 \mathrm{H}, \mathrm{m}, \mathrm{ArH}), 7.16(2 \mathrm{H}, \mathrm{d}, J=7.32 \mathrm{~Hz}$, ArH), 7.21-7.26 (2H, m, ArH), $7.44(2 \mathrm{H}, \mathrm{d}, J=8.05 \mathrm{~Hz}, \mathrm{ArH})$, $7.55(2 \mathrm{H}, \mathrm{d}, J=8.05 \mathrm{~Hz}, \mathrm{ArH}), 8.03(1 \mathrm{H}, \mathrm{d}, J=16.11 \mathrm{~Hz}$, $\alpha-\mathrm{H}), 8.51(1 \mathrm{H}, \mathrm{d}, J=16.11 \mathrm{~Hz}, \beta-\mathrm{H}), 16.84(1 \mathrm{H}, \mathrm{s},-\mathrm{OH})$; ${ }^{13} \mathrm{C}$ NMR $\left(100 \mathrm{MHz}, \mathrm{CDCl}_{3}\right): \delta(\mathrm{ppm}) 21.63\left(-\mathrm{CH}_{3}\right), 56.14$ $\left(-\mathrm{OCH}_{3}\right), 119.57,121.06,121.19,128.57,129.53,129.72,129.82$, $130.22,130.59,131.96,142.46,147.83,159.53,168.40,178.54$ $(\mathrm{C}=\mathrm{S}), 184.94$.

3.3. General Procedure for the Synthesis of Pyrimidine Pyrazole Heterocycles $(\mathbf{5 a}-\mathbf{l})$. To the mixture of corresponding chalcone $4 \mathrm{a}-\mathbf{l}(1 \mathrm{mmol})$ and phenylhydrazine $(1.5 \mathrm{mmol})$ in $20 \mathrm{~mL}$ of 1,4-dioxane, 2 drops of acetic acid were added. The reaction mixture was refluxed at $110^{\circ} \mathrm{C}$ overnight. After completion of reaction as monitored by TLC, reaction mixture was concentrated and extracted with chloroform $(3 \times 20 \mathrm{~mL})$. The combined organic extract was dried over anhydrous sodium sulphate and concentrated under reduced pressure. The crude product was purified by column chromatography ( $40 \%$ Ethyl acetate: pet ether). 
3.3.1. 1,3-Dimethyl-6-hydroxy-2,4-dioxo-5-(1'-phenyl-3'-(p-tolyl)-1H-pyrazol-5' -yl)-1,2,3,4 tetrahydropyrimidine, (5a). The product was obtained as mentioned in general procedure from 4a as white solid; M.p. $150-152^{\circ} \mathrm{C}$; IR $v_{\max }\left(\mathrm{cm}^{-1}\right)$ 1646, 1702, $(2 \times \mathrm{C}=\mathrm{O}), 2924(\mathrm{C}-\mathrm{H}), 3210(-\mathrm{OH}) ;{ }^{1} \mathrm{H}$ NMR $\left(400 \mathrm{MHz}, \mathrm{CDCl}_{3}\right): \delta(\mathrm{ppm}) 2.34\left(3 \mathrm{H}, \mathrm{s},-\mathrm{CH}_{3}\right), 3.28(3 \mathrm{H}$, s, N-CH $\left.\mathrm{CH}_{3}\right), 3.36\left(3 \mathrm{H}, \mathrm{s}, \mathrm{N}-\mathrm{CH}_{3}\right), 6.93(2 \mathrm{H}, \mathrm{d}, J=8.08 \mathrm{~Hz}$, $\mathrm{ArH}), 7.06(1 \mathrm{H}, \mathrm{t}, \mathrm{ArH}), 7.18(2 \mathrm{H}, \mathrm{d}, J=8.08 \mathrm{~Hz}, \mathrm{ArH})$, 7.25-7.30 (4H, m, Pyrazole H, ArH), $12.85(1 \mathrm{H}, \mathrm{s},-\mathrm{OH})$; ${ }^{13} \mathrm{C}$ NMR $\left(100 \mathrm{MHz}, \mathrm{CDCl}_{3}\right): \delta(\mathrm{ppm}) 21.04\left(-\mathrm{CH}_{3}\right), 27.51$ $\left(\mathrm{N}-\mathrm{CH}_{3}\right), 107.42,115.89,126.00,129.46,129.57,129.79,139.19$, 147.81, 153.50, 159.21, 165.28; ESI-MS $m / z:[\mathrm{M}+\mathrm{H}]^{+}=388.1$.

3.3.2.1,3-Dimethyl-6-hydroxy-2,4-dioxo-5-(1'-phenyl-3'-(p-methoxyphenyl)-1H-pyrazol-5'-yl)-1,2,3,4-tetrahydropyrimidine,

$(\mathbf{5 b})$. The product was obtained as mentioned in general procedure from $\mathbf{4 b}$ aslight brown solid, M.p. $170-171^{\circ} \mathrm{C}$; IR $\nu_{\max }\left(\mathrm{cm}^{-1}\right) 1647,1716(2 \times \mathrm{C}=\mathrm{O}), 2924(\mathrm{C}-\mathrm{H}), 3245(-\mathrm{OH})$; ${ }^{1} \mathrm{H}$ NMR $\left(400 \mathrm{MHz}, \mathrm{CDCl}_{3}\right): \delta(\mathrm{ppm}) 3.35\left(3 \mathrm{H}, \mathrm{s}, \mathrm{N}-\mathrm{CH}_{3}\right)$, $3.39\left(3 \mathrm{H}, \mathrm{s}, \mathrm{N}-\mathrm{CH}_{3}\right), 3.80\left(3 \mathrm{H}, \mathrm{s},-\mathrm{OCH}_{3}\right), 6.89-6.94(4 \mathrm{H}, \mathrm{m}$, $\mathrm{ArH}), 7.07$ (1H, t, ArH), 7.25-7.33 (5H, m, pyrazole $\mathrm{H}, \mathrm{ArH})$, $12.83(1 \mathrm{H}, \mathrm{s},-\mathrm{OH}) ;{ }^{13} \mathrm{C}$ NMR $\left(100 \mathrm{MHz}, \mathrm{CDCl}_{3}\right): \delta(\mathrm{ppm})$ $27.65\left(\mathrm{~N}-\mathrm{CH}_{3}\right), 29.67\left(\mathrm{~N}-\mathrm{CH}_{3}\right), 55.33\left(-\mathrm{OCH}_{3}\right), 86.08$, $114.45,116.27,124.13,127.47,129.54,132.39,148.08,151.88$, 159.61, 161.54, 162.08, 165.49; ESI-MS $m / z:[\mathrm{M}+\mathrm{H}]^{+}=404.1$.

3.3.3.1,3-Dimethyl-6-hydroxy-2,4-dioxo-5-(1'-phenyl-3'-(p-bromo)-1H-pyrazol-5'-yl)-2,4-dioxo-1,2,3,4-tetrahydropyrimidine, $(5 c)$. The product was obtained as mentioned in general procedure from $4 \mathrm{c}$ as white solid, M.p. $197-198^{\circ} \mathrm{C}$; IR $v_{\max }$ $\left(\mathrm{cm}^{-1}\right)$ 1699, $1734(2 \times \mathrm{C}=\mathrm{O}), 2925(\mathrm{C}-\mathrm{H}), 3417(-\mathrm{OH}) ;{ }^{1} \mathrm{H}$ NMR $\left(400 \mathrm{MHz}, \mathrm{CDCl}_{3}\right): \delta(\mathrm{ppm}) 3.28\left(3 \mathrm{H}, \mathrm{s}, \mathrm{N}-\mathrm{CH}_{3}\right)$, $3.35\left(3 \mathrm{H}, \mathrm{s}, \mathrm{N}-\mathrm{CH}_{3}\right), 6.92(2 \mathrm{H}, \mathrm{d}, J=8.05 \mathrm{~Hz}, \mathrm{ArH}), 7.09$ $(1 \mathrm{H}, \mathrm{t}, \mathrm{ArH}), 7.27-7.31(5 \mathrm{H}, \mathrm{m}$, Pyrazole H, ArH $), 7.52(2 \mathrm{H}, \mathrm{d}$, $J=8.05 \mathrm{~Hz}, \mathrm{ArH}), 12.82(1 \mathrm{H}, \mathrm{s},-\mathrm{OH}) ;{ }^{13} \mathrm{C}$ NMR $(100 \mathrm{MHz}$, $\left.\mathrm{CDCl}_{3}\right): \delta(\mathrm{ppm}) 27.84\left(\mathrm{~N}-\mathrm{CH}_{3}\right), 86.14,116.18,122.26,124.36$, $127.87,129.66,132.29,139.77,147.76,151.45,161.45,161.95$, 164.99; ESI-MS $m / z:[\mathrm{M}+\mathrm{H}]^{+}=453.3$.

3.3.4. 1,3-Dimethyl-6-hydroxy-2, 4-dioxo-5-(1' -phenyl-3' - (pchloro)-1H-pyrazol-5'-yl)-1,2,3,4-tetrahydropyrimidine, (5d). The product was obtained as mentioned in general procedure from $4 \mathbf{d}$ as light brown solid, M.p. 121-123 ${ }^{\circ} \mathrm{C}$; IR $\nu_{\max }\left(\mathrm{cm}^{-1}\right)$ 1642, $1702(2 \times \mathrm{C}=\mathrm{O}), 2923(\mathrm{C}-\mathrm{H}), 3319(-\mathrm{OH}) ;{ }^{1} \mathrm{H}$ NMR $\left(400 \mathrm{MHz}, \mathrm{CDCl}_{3}\right): \delta(\mathrm{ppm}) 3.28\left(3 \mathrm{H}, \mathrm{s}, \mathrm{N}-\mathrm{CH}_{3}\right), 3.36(3 \mathrm{H}$, s, $\left.\mathrm{N}-\mathrm{CH}_{3}\right), 6.92(2 \mathrm{H}, \mathrm{d}, J=8.05 \mathrm{~Hz}, \mathrm{ArH}), 7.07-7.11(2 \mathrm{H}$, $\mathrm{m}, \mathrm{ArH}), 7.24-7.48(6 \mathrm{H}, \mathrm{m}, \mathrm{ArH}$, pyrazole $\mathrm{H}), 12.83(1 \mathrm{H}$, $\mathrm{s},-\mathrm{OH}) ;{ }^{13} \mathrm{C}$ NMR $\left(100 \mathrm{MHz}, \mathrm{CDCl}_{3}\right): \delta(\mathrm{ppm}) 27.71(\mathrm{~N}-$ $\left.\mathrm{CH}_{3}\right), 87.69,116.27,119.88,121.09,124.36,125.04,127.56,129.00$, $129.33,129.49,130.04,134.16,139.09,147.62$, 151.71, 161.40; ESIMS $m / z:[\mathrm{M}+\mathrm{H}]^{+}=408.1$.

3.3.5. 1,3-Diphenyl-6-hydroxy-4-oxo-2- thiooxo-5-(1' - phenyl$3^{\prime}$-(p-tolyl)-1H-pyrazol-5'-yl)-1,2,3,4-tetrahydropyrimidine, (5e). The product was obtained as mentioned in general procedure from 4e as light brown solid, M.p. $131-133^{\circ} \mathrm{C}$; IR $\nu_{\max }\left(\mathrm{cm}^{-1}\right)$ $1071(\mathrm{C}=\mathrm{S}), 1676$ (C=O), $2924(\mathrm{C}-\mathrm{H}), 3245(-\mathrm{OH}) ;{ }^{1} \mathrm{H}$ NMR $\left(400 \mathrm{MHz}, \mathrm{CDCl}_{3}\right): \delta(\mathrm{ppm}) 2.35\left(3 \mathrm{H}, \mathrm{s},-\mathrm{CH}_{3}\right), 6.90(2 \mathrm{H}, \mathrm{d}$, $J=8.08 \mathrm{~Hz}, \mathrm{ArH}), 7.06(1 \mathrm{H}, \mathrm{t}, \mathrm{ArH}), 7.17-7.30(9 \mathrm{H}, \mathrm{m}, \mathrm{ArH})$, 7.32-7.38 (3H, m, ArH), 7.40-7.53 (5H, m, Pyrazole H, ArH), $12.82(1 \mathrm{H}, \mathrm{s},-\mathrm{OH}) ;{ }^{13} \mathrm{C}$ NMR $\left(100 \mathrm{MHz}, \mathrm{CDCl}_{3}\right): \delta(\mathrm{ppm})$ $21.24\left(\mathrm{~N}-\mathrm{CH}_{3}\right), 88.32,124.27,125.55,128.32,128.70,128.86$, $129.38,129.55,129.82,137.48,138.25,139.53,140.35,146.93$, $160.75,161.33,163.97,180.24(\mathrm{C}=\mathrm{S})$; ESI-MS $m / z:[\mathrm{M}+\mathrm{H}]^{+}=$ 528.1 .

3.3.6. 1,3-Diphenyl-6-hydroxy-4-oxo-2-thiooxo-5-(1'-phenyl$3^{\prime}$-(p-methoxyphenyl)-1H-pyrazol-5'-yl)-1,2,3,4-tetrahydropyrimidine, $(\mathbf{5 f})$. The product was obtained as mentioned in general procedure from $\mathbf{4 f}$ as green solid, M.p. $120-121^{\circ} \mathrm{C}$; IR $v_{\max }\left(\mathrm{cm}^{-1}\right) 1030(\mathrm{C}=\mathrm{S}), 1676(\mathrm{C}=\mathrm{O}), 2924(\mathrm{C}-\mathrm{H}), 3214$ $(-\mathrm{OH}) ;{ }^{1} \mathrm{H}$ NMR $\left(400 \mathrm{MHz}, \mathrm{CDCl}_{3}\right): \delta(\mathrm{ppm}) 3.82(3 \mathrm{H}, \mathrm{s}$, $\left.-\mathrm{OCH}_{3}\right), 6.90-6.93(4 \mathrm{H}, \mathrm{m}, \mathrm{ArH}), 7.08$ (1H, t, ArH), 7.21-7.40 $(10 \mathrm{H}, \mathrm{m}, \mathrm{ArH}), 7.43-7.58$ (5H, m, Pyrazole H, ArH), 12.83 $(1 \mathrm{H}, \mathrm{s},-\mathrm{OH}) ;{ }^{13} \mathrm{C}$ NMR $\left(100 \mathrm{MHz}, \mathrm{CDCl}_{3}\right): \delta(\mathrm{ppm}) 55.32$ $\left(-\mathrm{OCH}_{3}\right), 88.35,114.49,116.41,127.45,128.68,129.37,129.44$, $129.47,129.53,131.2,139.76,140.32,147.13,159.80,160.86$, $161.49,164.09,180.03(\mathrm{C}=\mathrm{S})$; ESI-MS $m / z:[\mathrm{M}+\mathrm{H}]^{+}=545.4$.

3.3.7. 1, 3-Diphenyl-6-hydroxy-4-oxo-2-thiooxo-5-(1'-phenyl$3^{\prime}$-(p-bromo)-1H-pyrazol-5'-yl)-1,2,3,4-tetrahydropyrimidine, $(5 \mathrm{~g})$. The product was obtained as mentioned in general procedure from $\mathbf{4 g}$ as light green solid, M.p. $209-210^{\circ} \mathrm{C}$; IR $\nu_{\max }\left(\mathrm{cm}^{-1}\right) 1071(\mathrm{C}=\mathrm{S}), 1675(\mathrm{C}=\mathrm{O}), 2925(\mathrm{C}-\mathrm{H}), 3182$ $(-\mathrm{OH}) ;{ }^{1} \mathrm{H}$ NMR $\left(400 \mathrm{MHz}, \mathrm{CDCl}_{3}\right): \delta(\mathrm{ppm}) 6.89(2 \mathrm{H}, \mathrm{d}$, $J=8.05 \mathrm{~Hz}, \mathrm{ArH}), 7.08(1 \mathrm{H}, \mathrm{t}, \mathrm{ArH}), 7.26-7.28(4 \mathrm{H}, \mathrm{m}, \mathrm{ArH})$, $7.33(2 \mathrm{H}, \mathrm{d}, J=7.32 \mathrm{~Hz}, \mathrm{ArH}), 7.40(2 \mathrm{H}, \mathrm{d}, J=8.05 \mathrm{~Hz}$, ArH), 7.44-7.57 (9H, m, Pyrazole $\mathrm{H}, \operatorname{ArH}), 12.80(1 \mathrm{H}, \mathrm{s}$, -OH); ${ }^{13} \mathrm{C}$ NMR $\left(100 \mathrm{MHz}, \mathrm{CDCl}_{3}\right.$ ): $\delta$ (ppm) 88.36, 106.31, $116.31,122.11,124.93,125.37,127.83,128.65,129.39,129.46$, $129.66,132.33,136.11,139.09,139.89,146.74,160.55,161.35$, 164.18, $179.92(\mathrm{C}=\mathrm{S})$; ESI-MS $m / z:[\mathrm{M}+\mathrm{H}]^{+}=592.0$.

3.3.8. 1,3-Diphenyl-6-hydroxy-4-oxo-2-thiooxo-5-(1'-phenyl$3^{\prime}$-(p-chloro)-1H-pyrazol-5'-yl)-1,2,3,4-tetrahydropyrimidine, $(\mathbf{5} \boldsymbol{h})$. The product was obtained as mentioned in general procedure from $4 \mathrm{~h}$ as dark green solid, M.p. $207-208^{\circ} \mathrm{C}$; IR $v_{\max }\left(\mathrm{cm}^{-1}\right) 1089(\mathrm{C}=\mathrm{S}), 1675(\mathrm{C}=\mathrm{O}), 2924(\mathrm{C}-\mathrm{H}), 3198$ $(-\mathrm{OH}) ;{ }^{1} \mathrm{H}$ NMR $\left(400 \mathrm{MHz}, \mathrm{CDCl}_{3}\right): \delta(\mathrm{ppm}) 6.89(2 \mathrm{H}, \mathrm{d}$, $J=8.05 \mathrm{~Hz}, \mathrm{ArH}), 7.08$ (1H, t ArH), 7.18-7.29 (5H, m, ArH), 7.32-7.40 (6H, m, ArH), 7.44-7.57 (6H, m, Pyrazole H, ArH), $12.80(1 \mathrm{H}, \mathrm{s},-\mathrm{OH}) ;{ }^{13} \mathrm{C}$ NMR $\left(100 \mathrm{MHz}, \mathrm{CDCl}_{3}\right): \delta(\mathrm{ppm})$ $88.50,105.95,116.30,127.51,128.64,129.39,129.47,129.65$, $134.23,138.66,139.48,139.89,146.59,160.96,161.35,164.21$, $179.94(\mathrm{C}=\mathrm{S})$; ESI-MS $m / z:[\mathrm{M}+\mathrm{H}]^{+}=548.1$.

3.3.9. 1,3-Bis(2" -methoxyphenyl)-6-hydroxy4-oxo-2-thioxo5-(1'-phenyl-3'-(p-tolyl)-1H-pyrazol-5'-yl)-1,2,3,4-tetrahydropyrimidine, (5i). The product was obtained as mentioned in general procedure from $4 \mathbf{i}$ as light brown solid, M.p. 107$109^{\circ} \mathrm{C}$; IR $v_{\max }\left(\mathrm{cm}^{-1}\right) 1075(\mathrm{C}=\mathrm{S}), 1677(\mathrm{C}=\mathrm{O}), 2925(\mathrm{C}-\mathrm{H})$, $3302(-\mathrm{OH}) ;{ }^{1} \mathrm{H}$ NMR $\left(400 \mathrm{MHz}, \mathrm{CDCl}_{3}\right): \delta$ (ppm) 2.36 $\left(3 \mathrm{H}, \mathrm{s},-\mathrm{CH}_{3}\right), 3.85\left(6 \mathrm{H}, \mathrm{s},-\mathrm{OCH}_{3}\right), 6.91(2 \mathrm{H}, \mathrm{d}, J=7.32 \mathrm{~Hz}$, ArH), 7.00-7.12 (6H, m, ArH), 7.18-7.30 (5H, m, ArH), 
7.30-7.43 (5H, m, Pyrazole H, ArH), $12.89(1 \mathrm{H}, \mathrm{s},-\mathrm{OH})$;

${ }^{13} \mathrm{C} \mathrm{NMR}\left(100 \mathrm{MHz}, \mathrm{CDCl}_{3}\right): \delta(\mathrm{ppm}) 29.61\left(-\mathrm{CH}_{3}\right), 56.01$ $\left(-\mathrm{OCH}_{3}\right), 85.53,105.37,112.20,112.72,115.94,121.02,125.57$, $128.51,129.56,129.67,129.79,129.99,140.16,148.36,154.66$, $178.37(\mathrm{C}=\mathrm{S})$; ESI-MS $m / z:[\mathrm{M}+\mathrm{H}]^{+}=588.1$.

3.3.10. 1,3-Bis(2" - methoxyphenyl)-6-hydroxy-4-oxo-2-thiooxo-5-(1'-phenyl-3'-(p-methoxyphenyl)-1H-pyrazol-5' $-y l)-1,2$, 3,4-tetrahydropyrimidine, (5j). The product was obtained as mentioned in general procedure from $\mathbf{4 j}$ as light green solid, M.p. $127-129^{\circ} \mathrm{C}$; IR $\nu_{\max }\left(\mathrm{cm}^{-1}\right) 1074(\mathrm{C}=\mathrm{S}), 1627(\mathrm{C}=\mathrm{O})$, $2926(\mathrm{C}-\mathrm{H}), 3422(-\mathrm{OH}) ;{ }^{1} \mathrm{H}$ NMR $\left(400 \mathrm{MHz}, \mathrm{CDCl}_{3}\right)$ : $\delta(\mathrm{ppm}) 3.83\left(9 \mathrm{H}, \mathrm{s},-\mathrm{OCH}_{3}\right), 6.83-6.92(7 \mathrm{H}, \mathrm{m}, \mathrm{ArH})$, 7.01-7.11 (7H, m, ArH), 7.20-7.32 $(4 \mathrm{H}, \mathrm{m}$, pyrazole $\mathrm{H}, \mathrm{ArH})$, $12.80(1 \mathrm{H}, \mathrm{s},-\mathrm{OH}) ;{ }^{13} \mathrm{C}$ NMR $\left(100 \mathrm{MHz}, \mathrm{CDCl}_{3}\right): \delta(\mathrm{ppm})$ $55.32\left(-\mathrm{OCH}_{3}\right), 88.15,112.78,113.53,114.45,116.33,121.01$, $121.53,121.81,124.32,127.53,129.16,129.46,129.84,130.18$, $146.75,154.93,159.55,167.76,185.32$ (C=S); ESI-MS $m / z$ : $[\mathrm{M}+\mathrm{H}]^{+}=604.1$.

3.3.11. 1,3-Bis ( $2^{\prime \prime}$-methoxyphenyl)-6-hydroxy-4-oxo-2-thiooxo-5-(1'-phenyl-3'-(p-bromo)-1H-pyrazol-5'-yl)-1,2,3,4-tetrahydropyrimidine, $(\mathbf{5} \boldsymbol{k})$. The product was obtained as mentioned in general procedure from $4 \mathbf{k}$ as light yellow solid, M.p. $112-113^{\circ} \mathrm{C}$; IR $v_{\max }\left(\mathrm{cm}^{-1}\right) 1044(\mathrm{C}=\mathrm{S}), 1674$ $(\mathrm{C}=\mathrm{O}), 2925(\mathrm{C}-\mathrm{H}), 3287(-\mathrm{OH}) ;{ }^{1} \mathrm{H}$ NMR $(400 \mathrm{MHz}$, $\left.\mathrm{CDCl}_{3}\right): \delta(\mathrm{ppm}) 3.78\left(6 \mathrm{H}, \mathrm{s},-\mathrm{OCH}_{3}\right), 6.82-6.84(2 \mathrm{H}, \mathrm{m}$, ArH), 6.93-7.04 (5H, m, ArH), 7.12-7.25 (6H, m, ArH), 7.32-7.39 (3H, m, ArH), 7.45-7.47 (2H, m, pyrazole $\mathrm{H}, \mathrm{ArH})$, $12.77(1 \mathrm{H}, \mathrm{s},-\mathrm{OH}) ;{ }^{13} \mathrm{C}$ NMR $\left(100 \mathrm{MHz}, \mathrm{CDCl}_{3}\right): \delta(\mathrm{ppm})$ $56.36\left(-\mathrm{OCH}_{3}\right), 88.36,116.26,121.03,121.13,127.90,128.00$, $129.60,129.70,129.89,130.25,132.30,139.30,139.36,146.77$, 154.51, 159.70, 160.94, 163.93, 179.53 (C=S); ESI-MS $m / z$ : $[\mathrm{M}+\mathrm{H}]^{+}=652.0$.

3.3.12. 1,3-Bis ( $2^{\prime \prime}$-methoxyphenyl)-4-oxo-2-thiooxo- 6-hydroxy-5-(1'-phenyl-3'-(p-chloro)-1H-pyrazol-5'-yl)-1,2,3,4-tetrahydropyrimidine, $(\mathbf{5 l})$. The product was obtained as mentioned in general procedure from $\mathbf{4} \mathbf{l}$ as light yellow solid, M.p. $232-233^{\circ} \mathrm{C}$; IR $v_{\max }\left(\mathrm{cm}^{-1}\right) 1043(\mathrm{C}=\mathrm{S}), 1654(\mathrm{C}=\mathrm{O})$, $2927(\mathrm{C}-\mathrm{H}), 3437(-\mathrm{OH}) ;{ }^{1} \mathrm{H}$ NMR $\left(400 \mathrm{MHz}, \mathrm{CDCl}_{3}\right)$ : $\delta(\mathrm{ppm}) 3.85\left(6 \mathrm{H}, \mathrm{s},-\mathrm{OCH}_{3}\right), 6.89-6.90(2 \mathrm{H}, \mathrm{m}, \mathrm{ArH})$, 6.98-7.09 (5H, m, ArH), 7.23-7.28 (5H, m, ArH), 7.33-7.45 $(6 \mathrm{H}, \mathrm{m}$, pyrazole $\mathrm{H}, \mathrm{ArH}), 12.83(\mathrm{H}, \mathrm{s},-\mathrm{OH}) ;{ }^{13} \mathrm{C}$ NMR $\left(100 \mathrm{MHz}, \mathrm{CDCl}_{3}\right): \delta(\mathrm{ppm}) 56.19\left(-\mathrm{OCH}_{3}\right), 88.18,112.23$, $116.06,120.91,124.52,127.60,129.34,129.59,129.88,134.26$, $138.88,154.89,160.60,163.97,185.19$ (C=S); ESI-MS $m / z$ : $[\mathrm{M}+\mathrm{H}]^{+}=609.3$.

3.4. Antifungal Susceptibility Test. The pathogenic isolates of Aspergillus fumigatus (ITCC 4517 (IARI, Indian Agricultural Research Institute Delhi), ITCC 1634 (IARI, Delhi), clinical isolate 190/96 (VPCI, Vallabhbhai Patel Chest Institute Delhi)), Aspergillus flavus (clinical isolate 223/96 (VPCI, Delhi)), and Aspergillus niger (clinical isolate 56/96 (VPCI, Delhi)) were employed in the current study. These pathogenic species of Aspergillus, namely, A. fumigatus, A. flavus, and
A. niger, were cultured in laboratory on Sabouraud dextrose (SD) agar plates. The plates were inoculated with stock cultures of A. fumigatus, A. flavus, and A. niger and incubated in a BOD incubator at $37^{\circ} \mathrm{C}$. The spores were harvested from $96 \mathrm{~h}$ cultures and suspended homogeneously in phosphate buffer saline (PBS). The spores in the suspension were counted and their number was adjusted to $10^{8}$ spores $/ \mathrm{mL}$ before performing the experiments. The antifungal activity of compounds was analysed by MDA, DDA, and PSGI. Each assay was repeated at least three times on different days. Amp $B$ was used as a standard drug in antifungal susceptibility test.

3.4.1. Disc Diffusion Assay (DDA). The disc diffusion assay was performed in radiation sterilized petri plates $(10.0 \mathrm{~cm}$ diameter, Tarsons). The SD agar plates were prepared and plated with a standardized suspension of $1 \times 10^{8}$ spore $/ \mathrm{mL}$ of Aspergillus spp. Then, plates were allowed to dry and discs $\{(5.0 \mathrm{~mm}$ in diameter $)$ of Whatman filter paper number $1\}$ were placed on the surface of the agar. The different concentrations of compounds in the range of 750-1.0046 $\mu \mathrm{g}$ were impregnated on the discs. An additional disc for solvent (DMSO) was also placed on agar plate. The plates were incubated at $37^{\circ} \mathrm{C}$ and examined at $24 \mathrm{~h}, 48 \mathrm{~h}$ for zone of inhibition, if any, around the discs. The concentration, which developed the zone of inhibition of at least $6.0 \mathrm{~mm}$ diameter, was taken as end point (Minimum Inhibitory Concentration, MIC).

3.4.2. Percent Spore Germination Inhibition Assay (PSGI). Different concentrations of the test compounds in $90.0 \mu \mathrm{L}$ of culture medium were prepared in 96-well flat-bottomed microculture plates (Tarson) by double dilution method. Each well was then inoculated with $10.0 \mu \mathrm{L}$ of spore suspension (100 \pm 5 spores). The plates were incubated at $37^{\circ} \mathrm{C}$ for $16 \mathrm{~h}$ and then examined for spore germination under inverted microscope (Nikon, diphot). The number of germinated and nongerminated spores was counted. The lowest concentration of the compound, which resulted in $>90 \%$ inhibition of germination of spores in the wells, was considered as $\mathrm{MIC}_{90}$.

3.4.3. Microbroth Dilution Assay (MDA). The test was performed in 96-well culture plates (Tarson). Various concentrations of compounds in the range of $1250-4.3 \mu \mathrm{g} / \mathrm{mL}$ were prepared in $90.0 \mu \mathrm{L}$ of culture medium by double dilution method. Each well was inoculated with $10 \mu \mathrm{L}$ of spore suspension $\left(1 \times 10^{8}\right.$ spore $\left./ \mathrm{mL}\right)$ and incubated for $48 \mathrm{~h}$ at $37^{\circ} \mathrm{C}$. After $48 \mathrm{~h}$, the plates were assessed visually. The optically clear well was taken as end point, MIC.

3.5. Antifungal Drugs and Pyrimidine Pyrazole Analogues Checkerboard Testing. In vitro combination of pyrimidine pyrazole analogues was studied with antifungal drug AmpB (Himedia) and NYS (Himedia). The starting range of final concentration was taken as approximate one fold higher than individual MIC to compute all in vitro interactions (Antagonistic; Synergy, SYN; and Indifference, IND). The final concentrations of antifungal agents which ranged 
from 3.125 to $0.02 \mu \mathrm{g} / \mathrm{mL}$ for Amp B, 6.25 to 0.09 for NYS, and 400 to $3.125 \mu \mathrm{g} / \mathrm{mL}$ for $\mathbf{5 c}, \mathbf{5 j}$ were taken. Aliquots of $45 \mu \mathrm{L}$ of each drug at a concentration four times the targeted final were dispensed in the wells in order to obtain a two-dimensional checkerboard $(8 \times 8$ combination) [27]. Each well then was inoculated with $10 \mu \mathrm{L}$ of spore suspension $\left(1 \times 10^{8}\right.$ spore $\left./ \mathrm{mL}\right)$. The plates were incubated at $37^{\circ} \mathrm{C}$ for $48 \mathrm{~h}$. The plates were then assessed visually. The optically clear well was taken as end point, MIC.

3.6. Drug Interaction Modelling. The drug interaction was determined by the most popular FICI model. The FICI represents the sum of the FICs (Fraction Inhibitory Concentration) of each drug tested. The FIC of a drug was defined as MIC of a drug in combination divided by MIC of the same drug alone (MIC of drug in combination/MIC of drug alone), FICI $=1$ (revealed indifference), FICI $\leq 0.5$ (revealed synergy), and FICI $>4$ (revealed antagonism) [28].

3.7. Antibacterial Susceptibility Test. The antibacterial activity of compound was analysed by microbroth dilution Resazurin based assay [29]. Each assay was repeated at least three times on different days. The different pathogenic species of bacteria, Staphylococcus aureus (MTCC number 3160), Bacillus cereus (MTCC number 10085), Escherichia coli (MTCC number 433), Salmonella typhi (MTCC number 733), Micrococcus luteus (MTCC number 8132), Bacillus pumilis (MTCC number 2299), and Bacillus subtilis (MTCC number 8142), were cultured in Luria broth. Using aseptic techniques, a single colony was transferred into a $100 \mathrm{~mL}$ Luria broth and placed in incubator at $35^{\circ} \mathrm{C}$. After $12-18 \mathrm{~h}$ of incubation, the culture was centrifuged at $4000 \mathrm{rpm}$ for 5 minutes. The supernatant was discarded and pellet was resuspended in $20 \mathrm{~mL}$ PBS and centrifuged again at $4000 \mathrm{rpm}$ for $5 \mathrm{~min}$. This step was repeated until the supernatant was clear. The pellet was then suspended in $20 \mathrm{~mL}$ PBS. The optical density of the bacteria was recorded at $500 \mathrm{~nm}$ and serial dilutions were carried out with appropriate aseptic techniques until the optical density was in the range of $0.5-1.0$, representing $5 \times 10^{6} \mathrm{CFU} / \mathrm{mL}$.

3.7.1. Resazurin Based Microtitre Dilution Assay. Resazurin based MDA was performed in 96-well plates under aseptic conditions. The concentrations of compounds in the range of $2000-7.8 \mu \mathrm{g} / \mathrm{mL}$ were prepared in $100 \mu \mathrm{L}$ of culture medium by serial dilution method. $10 \mu \mathrm{L}$ of Resazurin indicator solution (5X) was added in each well. Finally, $10 \mu \mathrm{L}$ of bacterial suspension was added $\left(5 \times 10^{6} \mathrm{CFU} / \mathrm{mL}\right)$ to each well to achieve a concentration of $5 \times 10^{5} \mathrm{CFU} / \mathrm{mL}$. Each plate had a set of controls: a column with erythromycin as positive control. The plates were prepared in triplicate and incubated at $37^{\circ} \mathrm{C}$ for $24 \mathrm{~h}$. The colour change was then assessed visually. The lowest concentration at which colour change occurred was taken as the MIC value.

\section{Conclusion}

In search of novel antimicrobial molecules, we came across that pyrimidine pyrazole heterocycles can be of interest as $\mathbf{5 g}$ showed significant antibacterial activity. The compounds 5e and $\mathbf{5 h}$ also showed moderate antibacterial activity. $\mathbf{5 j}$ showed moderate antifungal activity. Out of all heterocycles, $\mathbf{5 c}$ possesses both antifungal and antibacterial activity. Our studies showed that these novel heterocycles can supplement the existing antifungal therapy. Monotherapy can be replaced by combination therapy. Therefore $\mathbf{5 c}, \mathbf{5 g}$, and $\mathbf{5 j}$ might be of great interest for the development of novel antimicrobial molecule.

\section{Conflict of Interests}

The authors declare that there is no conflict of interests regarding the publication of this paper.

\section{Acknowledgments}

The authors would like to thank Council of Scientific and Industrial Research (CSIR), New Delhi, and Defence Research and Development Organisation (DRDO) for the financial support.

\section{References}

[1] A. L. Stuart, N. K. Ayisi, G. Tourigny, and V. S. Gupta, "Antiviral activity, antimetabolic activity and cytotoxicity of 3/-substituted deoxypyrimidine nucleosides," Journal of Pharmaceutical Sciences, vol. 74, no. 3, pp. 246-249, 1985.

[2] A. Agarwal, N. Goyal, P. M. S. Chauhan, and S. Gupta, "Dihydropyrido[2,3-d]pyrimidines as a new class of antileishmanial agents," Bioorganic and Medicinal Chemistry, vol. 13, no. 24, pp. 6678-6684, 2005.

[3] R. E. Mitchell, D. R. Greenwood, and V. Sarojini, "An antibacterial pyrazole derivative from Burkholderia glumae, a bacterial pathogen of rice," Phytochemistry, vol. 69, no. 15, pp. 2704-2707, 2008.

[4] R. Basawaraj, B. Yadav, and S. S. Sangapure, "Synthesis of some $1 \mathrm{H}$-pyrazolines bearing benzofuran as biologically active agents," Indian Journal of Heterocyclic Chemistry, vol. 11, no. 1, pp. 31-34, 2001.

[5] K. T. Ashish and M. Anil, "Synthesis and antifungal activity of 4-substituted-3,7-dimethylpyrazolo [3,4-e] [1,2,4] triazine," Indian Journal of Chemistry B, vol. 45, p. 489, 2006.

[6] B. P. Chetan and V. V. Mulwar, "Synthesis and evaluation of certain pyrazolines and related compounds for their anti tubercular, anti bacterial and anti fungal activities," Indian Journal of Chemistry B, vol. 44, article 232, 2000.

[7] K. S. Nimavat and K. H. Popat, "Synthesis, anticancer, antitubercular and antimicrobial activities of 1-substituted, 3-aryl5-(3'-bromophenyl) pyrazoline," Indian Journal of Heterocyclic Chemistry, vol. 16, p. 333, 2007.

[8] R. H. Udupi, A. R. Bhat, and K. Krishna, "Synthesis and investigation of some new pyrazoline derivatives for their antimicrobial, anti inflammatory and analgesic activities," Indian Journal of Heterocyclic Chemistry, vol. 8, p. 143, 1998. 
[9] F. R. Souza, V. T. Souza, V. Ratzlaff et al., "Hypothermic and antipyretic effects of 3-methyl- and 3-phenyl-5-hydroxy-5trichloromethyl-4,5-dihydro- $1 H$-pyrazole-1-carboxyamides in mice," European Journal of Pharmacology, vol. 451, no. 2, pp. 141147, 2002.

[10] K. Ashok, Archana, and S. Sharma, "Synthesis of potential quinazolinyl pyrazolines as anticonvulsant agents," Indian Journal of Heterocyclic Chemistry, vol. 9, p. 197, 2001.

[11] M. Abdel-Aziz, G. E. A. Abuo-Rahma, and A. A. Hassan, "Synthesis of novel pyrazole derivatives and evaluation of their antidepressant and anticonvulsant activities," European Journal of Medicinal Chemistry, vol. 44, no. 9, pp. 3480-3487, 2009.

[12] L. A. Elvin, E. C. John, C. G. Leon, J. L. John, and H. E. Reiff, "Synthesis and muscle relaxant property of 3-amino-4aryl pyrazoles," Journal of Medicinal Chemistry, vol. 7, no. 3, pp. 259-268, 1964.

[13] G. Doria, C. Passarotti, R. Sala et al., "Synthesis and antiulcer activity of (E)-5-[2-(3-pyridyl) ethenyl ]-1 H,7 H-pyrazolo [1,5a] pyrimidine-7-ones," Farmaco, vol. 41, p. 417, 1986.

[14] W. H. Robert, "The antiarrhythmic and antiinflammatory activity of a series of tricyclic pyrazoles," Journal of Heterocyclic Chemistry, vol. 13, no. 3, pp. 545-553, 2009.

[15] R. Soliman, H. Mokhtar, and H. F. Mohamed, "Synthesis and antidiabetic activity of some sulfonylurea derivatives of 3,5disubstituted pyrazoles," Journal of Pharmaceutical Sciences, vol. 72, no. 9, pp. 999-1004, 1983.

[16] R. Kumar, J. Arora, A. K. Prasad, N. Islam, and A. K. Verma, "Synthesis and antimicrobial activity of pyrimidine chalcones," Medicinal Chemistry Research, vol. 22, no. 11, pp. 5624-5631, 2013.

[17] A. Solankee, S. Lad, S. Solankee, and G. Patel, "Chalcones, pyrazolines and aminopyrimidines as antibacterial agents," Indian Journal of Chemistry B, vol. 48, article 1442, 2009.

[18] B. S. Jursic and D. M. Neumann, "Preparation of 5-formyland 5-acetylbarbituric acids, including the corresponding Schiff bases and phenylhydrazones," Tetrahedron Letters, vol. 42, no. 48, pp. 8435-8439, 2001.

[19] F. S. Crossley, E. Miller, W. H. Hartung, and M. L. Moore, “Thiobarbiturates. III. Some N-substituted derivatives," Journal of Organic Chemistry, vol. 5, no. 3, pp. 238-243, 1940.

[20] P. Cabildo, R. M. Claramunt, and J. Elguero, " ${ }^{13}$ C NMR chemical shifts of N-unsubstituted and N-methyl-pyrazole derivatives," Organic Magnetic Resonance, vol. 22, no. 9, pp. 603607, 1984.

[21] V. Yadav, J. Gupta, R. Mandhan et al., "Investigations on antiAspergillus properties of bacterial products," Letters in Applied Microbiology, vol. 41, no. 4, pp. 309-314, 2005.

[22] S. Ruhil, M. Balhara, S. Dhankhar, M. Kumar, V. Kumar, and A. K. Chhillar, "Advancement in infection control of opportunistic pathogen (Aspergillus spp.): adjunctive agents," Current Pharmaceutical Biotechnology, vol. 14, no. 2, pp. 226232, 2013

[23] T. R. T. Dagenais and N. P. Keller, "Pathogenesis of Aspergillus fumigatus in invasive aspergillosis," Clinical Microbiology Reviews, vol. 22, no. 3, pp. 447-465, 2009.

[24] J. Smith and D. Andes, "Therapeutic drug monitoring of antifungals: pharmacokinetic and pharmacodynamic considerations," Therapeutic Drug Monitoring, vol. 30, no. 2, pp. 167-172, 2008.

[25] S. Bondock, W. Khalifa, and A. A. Fadda, "Synthesis and antimicrobial activity of some new 4-hetarylpyrazole and furo[2,3-c]pyrazole derivatives," European Journal of Medicinal Chemistry, vol. 46, no. 6, pp. 2555-2561, 2011.

[26] K. S. Jain, T. S. Chitre, P. B. Miniyar et al., "Biological and medicinal significance of pyrimidines," Current Science, vol. 90, no. 6, pp. 793-803, 2006.

[27] E. M. O’Shaughnessy, J. Meletiadis, T. Stergiopoulou, J. P. Demchok, and T. J. Walsh, "Antifungal interactions within the triple combination of amphotericin $\mathrm{B}$, caspofungin and voriconazole against Aspergillus species," Journal of Antimicrobial Chemotherapy, vol. 58, no. 6, pp. 1168-1176, 2006.

[28] S. Ruhil, M. Balhara, S. Dhankhar, V. Kumar, and A. K. Chhillar, "Invasive aspergillosis: adjunctive combination therapy," MiniReviews in Medicinal Chemistry, vol. 12, no. 12, pp. 1261-1272, 2012.

[29] S. Dhankhar, M. Kumar, S. Ruhil, M. Balhara, and A. K. Chhillar, "Analysis toward innovative herbal antibacterial \& antifungal drugs," Recent Patents on Anti-Infective Drug Discovery, vol. 7, no. 3, pp. 242-248, 2012. 

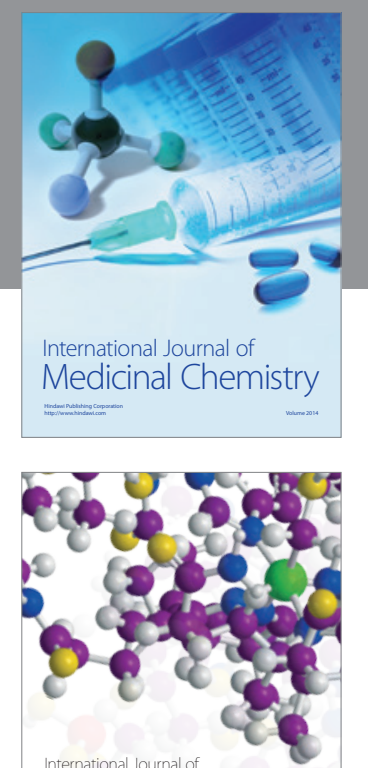

\section{Carbohydrate} Chemistry

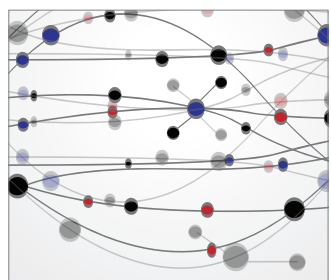

The Scientific World Journal
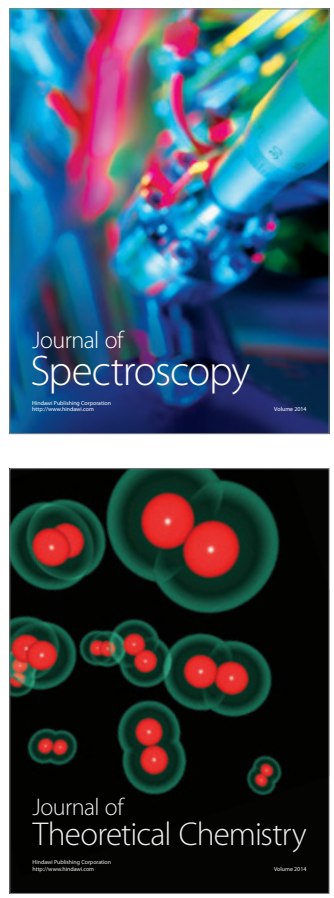
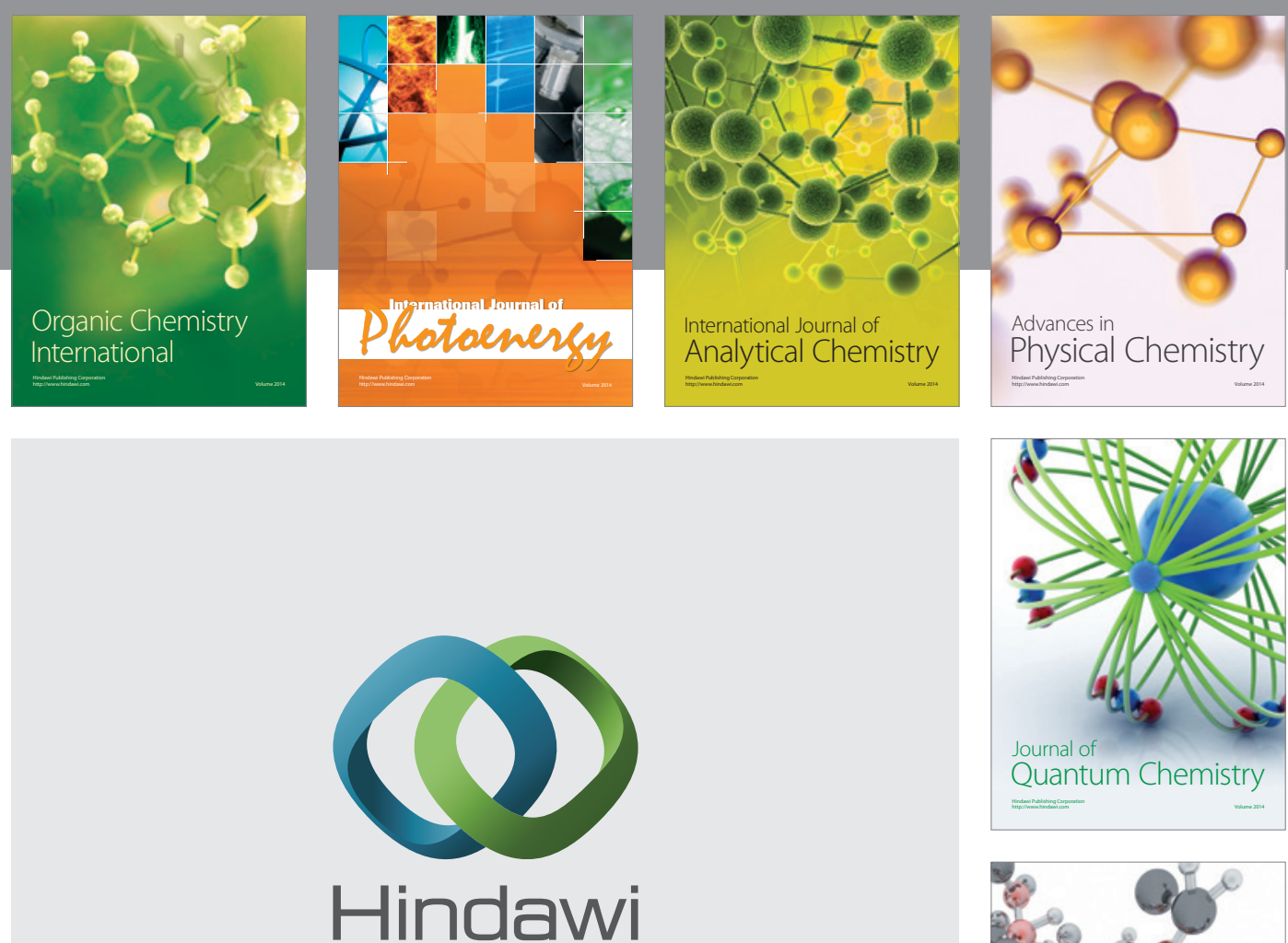

Submit your manuscripts at

http://www.hindawi.com

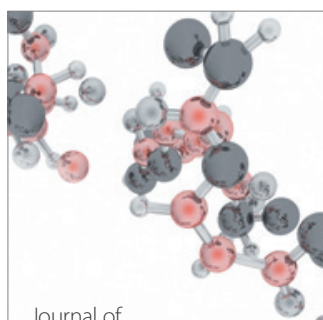

Analytical Methods

in Chemistry

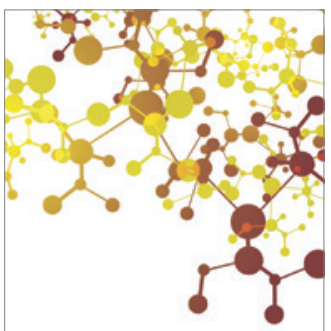

Journal of

Applied Chemistry

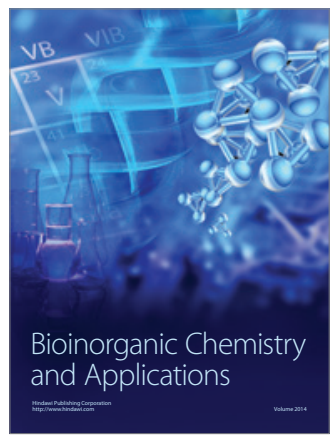

Inorganic Chemistry
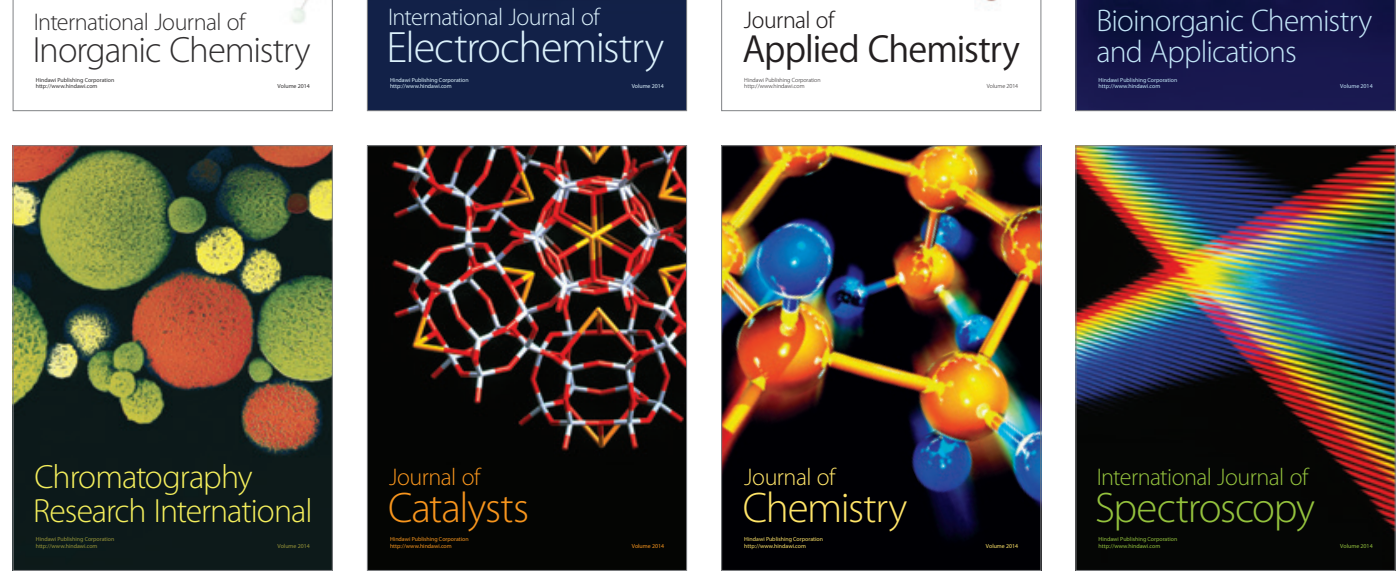